\title{
La academia y la publicación científica, un punto de partida
}

J. Selva Andina Anim. Sci. 2021; 8(2):56-56.

La edición de este número trata de temas relacionados a la Medicina Veterinaria y la Zootecnia, una de las razones y/o elementos vitales de la vida académica se centra en la investigación, que concluye en la publicación como resultado de un trabajo que rescata su aporte profesional, sin embargo, se puede decir sin reservas, que gran parte de la vida académica está condicionada por la publicación en algunas universidades de la región. De ahí que no en vano los profesores son evaluados conforme al volumen de publicaciones que generen, siendo fundamentales para el desarrollo y su promoción, además del aporte a la sociedad. Sin embargo, hay que hacer notar, que la capacidad de publicación no necesariamente significa capacidad de difusión, dado que en algunas universidades no hay el insensivo y menos un estímulo, situación muy común en nuestro medio, si bien uno desea realizar una investigación, el apoyo financiero se vuelve en una limitante y muchas veces la buena intención del profesor solo llega hasta donde le permite, y muchas veces no se concluye por la falta de recursos. Pero la labor académica debería gravitar entre la investigación-docencia-publicación, conformando una unidad de acción, como cimiento base en el quehacer real del investigador, de ahí que el aporte para el estudiante de pregrado o postgrado que eleven su nivel académico, permitiéndole reflexionar sobre sus inquietudes intelectuales y científicas en la medida en que se investiga, lo que permitiría al profesor reflexionar sobre sus inquietudes intelectuales y científicas en la medida que investigue y trasfiera esas inquietudes y capacidades a un auditorio, de esta manera se logra un acercamiento al estudiante a su realidad con conociendo extraído de sus experiencias, superando el conformismo tradicional.

Más allá de los conceptos y misión que tiene la Universidad en su conjunto, no se debe dejar de lado la extensión, este es un espacio valioso de desarrollo creativo, y porque no decirlo abre una oportunidad para la generación de investigaciones, aquí la creatividad del profesor es fundamental para hacer atractiva esta actividad a los estudiantes, de ahí que la extensión universitaria representa una posibilidad real para la generación de nuevo conocimiento y por ende resolver problemas que aqueja la sociedad de manera integral, poniendo en evidencia el trabajo, capacidad, experiencia y creatividad del profesor universitario, obviamente que lograr esta actividad debe ser vista por docentes que tiene ese ánimo de hacerlo, pues si solo es ir para hacer presencia no sería lo más aconsejable y perdería su virtud este espacio.

Loza-Murguía Manuel Gregorio PhD

Director - Editor en Jefe Presidente Ejecutivo - Honorario Junta Directiva Consejo Superior de Investigación en Ciencia \& Biotecnología

Fundación Selva Andina Research Society Dirección de contacto: +591-67110665-75214458

E-mail: directoreditoranimalscience@ gmail.com boliviamanloza@yahoo.com 2021. Journal of the Selva Andina Animal Science ${ }^{\circledR}$. Bolivia. Todos los derechos reservados. 